Fixed Point Theory, 20(2019), No. 2, 663-682

DOI: $10.24193 /$ fpt-ro.2019.2.44

http://www.math.ubbcluj.ro/ nodeacj/sfptcj.html

\title{
NONLINEAR ITERATION METHOD FOR MONOTONE VARIATIONAL INEQUALITY AND FIXED POINT PROBLEM
}

\author{
YEKINI SHEHU \\ Department of Mathematics, University of Nigeria, Nsukka, Nigeria \\ E-mail: yekini.shehu@unn.edu.ng
}

\begin{abstract}
Using the subgradient extragradient and Halpern methods, we prove two strong convergence results for finding a solution of a variational inequality problem involving Lipschitz continuous monotone with the Lipschitz constant unknown and the solution is also a fixed point a quasi-nonexpansive mapping in real Hilbert space.

Key Words and Phrases: Monotone mappings, subgradient extragradient method, Halpern method, quasi-nonexpansive mapping, strong convergence, fixed point, Hilbert spaces.

2010 Mathematics Subject Classification: 49J53, 65K10, 49M37, 90C25, 47H10.

Acknowledgment. The research was carried out when the author was an Alexander von Humboldt Postdoctoral Fellow at the Institute of Mathematics, University of Wurzburg, Germany. He is grateful to the Alexander von Humboldt Foundation, Bonn for the fellowship and the Institute of Mathematics, University of Wurzburg, Germany for the hospitality and facilities.
\end{abstract}

\section{REFERENCES}

[1] A.S. Antipin, On a method for convex programs using a symmetrical modification of the lagrange function, Ekonomika i Matematicheskie Metody, 12(1976), 1164-1173.

[2] R.Y. Apostol, A.A. Grynenko, V.V. Semenov, Iterative algorithms for monotone bilevel variational inequalities, J. Comput. Appl. Math., 107(2012), 3-14.

[3] J.-P. Aubin, I. Ekeland, Applied Nonlinear Analysis, Wiley, New York, 1984.

[4] C. Baiocchi, A. Capelo, Variational and Quasivariational Inequalities; Applications to Free Boundary Problems, Wiley, New York, 1984.

[5] H.H. Bauschke, P.L. Combettes, Convex Analysis and Monotone Operator Theory in Hilbert Spaces, CMS Books in Mathematics, Springer, New York, 2011.

[6] A. Bnouhachem, A self-adaptive method for solving general mixed variational inequalities, J. Math. Anal. Appl., 309(2005) 136-150.

[7] L.-C. Ceng, N. Hadjisavvas, N.-C. Wong, Strong convergence theorem by a hybrid extragradientlike approximation method for variational inequalities and fixed point problems, J. Global Optim., 46(2010), 635-646.

[8] Y. Censor, A. Gibali, S. Reich, Strong convergence of subgradient extragradient methods for the variational inequality problem in Hilbert space, Optim. Methods Software, 26(2011), 827-845.

[9] Y. Censor, A. Gibali, S. Reich, The subgradient extragradient method for solving variational inequalities in Hilbert space, J. Optim. Theory Appl., 148(2011), 318-335. 
[10] F. Facchinei, J.-S. Pang, Finite-Dimensional Variational Inequalities and Complementarity Problems, Vol. II, Springer Series in Operations Research, Springer, New York, 2003.

[11] C. Fang, S. Chen, Some extragradient algorithms for variational inequalities, Advances in Variational and Hemivariational Inequalities, 145-171, Adv. Mech. Math., 33, Springer, Cham, 2015.

[12] R. Glowinski, J.-L. Lions, R. Tremolier's, Numerical Analysis of Variational Inequalities, NorthHolland, Amsterdam, 1981.

[13] Y. He, A new double projection algorithm for variational inequalities, J. Comput. Appl. Math., 185(2006), 166-173.

[14] B.-S. He, Z.-H. Yang, X.-M. Yuan, An approximate proximal-extragradient type method for monotone variational inequalities, J. Math. Anal. Appl., 300(2004), 362-374.

[15] A.N. Iusem, M. Nasri, Korpelevich's method for variational inequality problems in Banach spaces, J. Global Optim., 50(2011), 59-76.

[16] A.N. Iusem, B.F. Svaiter, A variant of Korpelevich's method for variational inequalities with a new search strategy, Optimization, 42(1997), 309-321.

[17] E.N. Khobotov, Modification of the extragradient method for solving variational inequalities and certain optimization problems, USSR Computational Mathematics and Mathematical Physics, 27(1989), 120-127.

[18] D. Kinderlehrer, G. Stampacchia, An Introduction to Variational Inequalities and Their Applications, Academic Press, New York, 1980.

[19] I.V. Konnov, Combined Relaxation Methods for Variational Inequalities, Springer-Verlag, Berlin, 2001.

[20] G.M. Korpelevich, The extragradient method for finding saddle points and other problems, Ekonomika i Matematicheskie Metody, 12(1976), 747-756.

[21] R. Kraikaew, S. Saejung, Strong convergence of the Halpern subgradient extragradient method for solving variational inequalities in Hilbert spaces, J. Optim. Theory Appl., 163(2014), 399412.

[22] S.I. Lyashko, V.V. Semenov, T.A. Voitova, Low-cost modification of Korpelevich's method for monotone equilibrium problems, Cybernetics and Systems Anal., 47(2011), 631-639.

[23] P.E. Mainge, A hybrid extragradient-viscosity method for monotone operators and fixed point problems, SIAM J. Control Optim., 47(2008), no. 3, 1499-1515.

[24] P.E. Mainge, Numerical approach to monotone variational inequalities by a one-step projected reflected gradient method with line-search procedure, Comput. Math. Appl., 72(2016), no. 3, 720-728.

[25] P.E. Mainge, M.L. Gobinddass, Convergence of one-step projected gradient methods for variational inequalities, J. Optim. Theory Appl., 171(2017), 146-168.

[26] Yu. V. Malitsky, V.V. Semenov, A hybrid method without extrapolation step for solving variational inequality problems, J. Global Optim., 61(2015), 193-202.

[27] N. Nadezhkina, W. Takahashi, Weak Convergence Theorem by an Extragradient Method for Nonexpansive Mappings and Monotone Mappings, J. Optim. Theory Appl., 128(2006), 191201.

[28] N. Nadezhkina, W. Takahashi, Strong convergence theorem by a hybrid method for nonexpansive mappings and Lipschitz-continuous monotone mappings, SIAM J. Optim., 16(2006), 1230-1241.

[29] A. Nagurney, Network Economics: A Variational Inequality Approach, Kluwer Academic Publishers, Dordrecht, 1999.

[30] Y. Shehu, O. S. Iyiola, Strong convergence result for monotone variational inequalities, Numer. Algor. 76 (2017), 259-282.

[31] M.V. Solodov, B.F. Svaiter, A new projection method for variational inequality problems, SIAM J. Control Optim., 37(1999), 765-776.

[32] W. Takahashi, Nonlinear Functional Analysis, Yokohama Publishers, Yokohama, 2000.

[33] P. Tseng, A modified forward-backward splitting method for maximal monotone mappings, SIAM J. Control Optim., 38(2000), 431-446.

[34] H.K. Xu, Iterative algorithm for nonlinear operators, J. London Math. Soc., 66(2002), no. 2, 1-17. 
Received: February 1st, 2017; Accepted: July 6, 2017. 
